\title{
Polytypic transformations during the thermal decomposition of cobalt hydroxide and cobalt hydroxynitrate
}

\author{
Thimmasandra Narayan Ramesh * \\ Department of Chemistry, Central College, Bangalore University, Bangalore 560 001, India
}

\section{A R T I C L E I N F O}

\section{Article history:}

Received 19 December 2009

Received in revised form

14 April 2010

Accepted 19 April 2010

Available online 24 April 2010

\section{Keywords:}

Cobalt hydroxide

Cobalt oxyhydroxide

Polytype

Thermal decomposition

DIFFaX simulation

Powder X-ray diffraction

\begin{abstract}
A B S T R A C T
The isothermal decomposition of cobalt hydroxide and cobalt hydroxynitrate at different intervals of temperature leads to the formation of $\mathrm{Co}_{3} \mathrm{O}_{4}$. The phase evolution during the decomposition process was monitored using powder X-ray diffraction. The transformation of cobalt hydroxide to cobalt oxide occurs via three phase mixture while cobalt hydroxynitrate to cobalt oxide occurs through a two phase mixture. The nature of the sample and its preparation method controls the decomposition mechanism. The comparison of topotactical relationship between the precursors to the decomposed product has been reported in relation to polytypism.
\end{abstract}

(c) 2010 Elsevier Inc. All rights reserved.

\section{Introduction}

The kinetics of thermal decomposition process in solid state materials has drawn considerable attention of materials chemists and chemical engineers [1]. The investigation on thermal decomposition mechanism of solids can provide an insight into the phase transformation process and the evolution of intermediate metastable phases. Metal hydroxide and hydroxysalts have been used in various applications such as catalysis, supercapacitors, rechargeable batteries, magnetic materials, ceramics, ion exchangers and organicinorganic nanohybrids [2-5]. The bivalent metal hydroxides and hydroxysalts derive their structure from mineral brucite- $-\mathrm{Mg}(\mathrm{OH})_{2}$ [6-8]. The crystal structure of bivalent metal hydroxide consists of a hexagonal close packing of hydroxyl ions, in which alternative layers of octahedral sites are occupied by the divalent metal ions. This results in the stacking of charge neutral hydroxide $\left[\mathrm{M}(\mathrm{OH})_{2}\right]$ sheets held together by van der Waal's interaction. A fraction of hydroxyl groups deficiency within the sheets creates positive charge on the metal hydroxide layers with the composition $\left[\mathrm{M}(\mathrm{OH})_{2-x}\right]^{x+}$. The hydroxyl deficiency was compensated by grafting anions to the metal ion. This results in an expansion of interlayer distance from 4.6 to $6.9 \AA$ with the general composition of $\left[\mathrm{M}(\mathrm{OH})_{2-x}\right]\left[\mathrm{A}_{n}{ }^{-}\right]_{x / n}[9]$. Cobalt hydroxide and cobalt hydroxynitrate $\left[\mathrm{CO}_{3}(\mathrm{OH})_{4}\left(\mathrm{NO}_{3}\right)_{2}\right]$ crystallizes in the mineral brucite structure $[10,11]$.

Cobalt hydroxide powder on heating in an oxygen atmosphere results in the formation of a mixture of cobalt hydroxide, cobalt

\footnotetext{
* Corresponding author.

E-mail addresses: adityaramesh77@yahoo.com, rameshtn77@gmail.com.
}

oxyhydroxide and $\mathrm{Co}_{3} \mathrm{O}_{4}$ [12]. The freshly precipitated cobalt hydroxide slurry on (i) exposure to air, (ii) ageing in alkaline solution or mother liquor results in the formation of $\mathrm{CoOOH}$ [13]. Nanocrystalline cobalt hydroxide platelets were prepared by the hydrothermal treatment technique in presence of amines and polyvinylpyrrolidine [14,15]. There are several reports on the thermal decomposition studies of cobalt hydroxide, cobalt oxyhydroxide and cobalt based layered double hydroxides in relation to texture, morphology by electron diffraction, X-ray diffraction, Raman spectroscopy and X-ray photoelectron spectroscopy [16-19]. The above studies on thermal decomposition of cobalt hydroxide and cobalt oxyhydroxide do not characterize the intermediate phases formed during the decomposition process. In this article we have investigated the thermal decomposition process of cobalt hydroxide and cobalt hydroxynitrate in relation to its structural evolution and polytypism. The evolution of intermediate phases during the thermal decomposition of cobalt hydroxide and cobalt hydroxynitrate was characterized by using the X-ray powder diffraction pattern. At $125^{\circ} \mathrm{C}$, cobalt hydroxide undergoes phase transition resulting in the formation of an intermediate mixture of different polytypic phases of cobalt hydroxide, cobalt oxyhydroxide and cobalt oxide. In order to understand the mechanism of the polytype evolution, X-ray powder diffraction patterns were simulated using the Diffracted Intensities from Faulted Xtals (DIFFaX) program.

\section{Experimental}

Cobalt hydroxide and cobalt hydroxynitrate samples were prepared by following the procedure reported elsewhere $[6,11]$. 
Cobalt nitrate solution $(1 \mathrm{M}, 50 \mathrm{~mL})$ was added to sodium hydroxide $(2 \mathrm{M}, 100 \mathrm{~mL})$ solution at $80^{\circ} \mathrm{C}$. The bluish green coloured precipitate formed changes to rose red colour on aging in mother liquor for $30 \mathrm{~min}$. Cobalt hydroxynitrate was prepared by heating the mixture of cobalt nitrate hexahydrate $(18 \mathrm{~g})$, urea $(2 \mathrm{~g})$ and distilled water $(5 \mathrm{~mL})$ at $140{ }^{\circ} \mathrm{C}$ for $1 \mathrm{~h}$. The products were washed with distilled water, rinsed with acetone and dried ambient temperature $\left(25^{\circ} \mathrm{C}\right)$.

All the samples were characterized by the powder X-ray diffraction (PXRD) using Bruker D8 diffractometer $(\mathrm{Cu} K \alpha$ source; $\lambda=1.5418 \AA$ ). Data were collected at a scan rate of $2^{\circ} \mathrm{min}^{-1}$ with $2 \theta$ steps of $0.05^{\circ}$. Thermogravimetric studies were performed with a Mettler Toledo Model 851e TG/SDTA system (heating rate of $10^{\circ} \mathrm{C} \mathrm{min}^{-1}$ under air from 25 to $650^{\circ} \mathrm{C}$. The wet chemical analysis of the samples was carried out following the procedure described elsewhere [11]. The chemical composition of cobalt hydroxide and cobalt hydroxynitrate are $\mathrm{Co}(\mathrm{OH})_{2}$ and $\mathrm{Co}_{2}(\mathrm{OH})_{3}$ $\left(\mathrm{NO}_{3}\right)$, respectively. Isothermal heating of cobalt hydroxide and cobalt hydroxynitrate samples were carried out at different intervals of temperature (room temperature (RT), 100, 125, 150, $180,210,250,225,300,400^{\circ} \mathrm{C}$ ) for $1 \mathrm{~h}$ each and then cooled to room temperature. The X-ray powder diffraction patterns of the heat treated samples were measured. In order to understand the phase evolution, X-ray powder diffraction patterns of cobalt hydroxide, cobalt hydroxynitrate with different type of polytypes and $\mathrm{Co}_{3} \mathrm{O}_{4}$ were simulated by using the DIFFaX code. The details about the PXRD simulations have been explicitly defined in the literature $[11,20]$. In brief, the DIFFaX program enables us to simulate the PXRD pattern of crystalline solids. The program treats the crystalline material in terms of stacking the layer of atoms on top of each other. The diffracted intensities from the layers were calculated and integrated over an $n$-number of layers, where $n$ can take a minimum value of two and extends to infinity. DIFFaX program provides an option to generate various polytypes by modifying the stacking sequence of layers. This enables us to simulate the PXRD pattern of different polytypes thereby assists to compare it with the observed PXRD patterns.

\section{Results and discussion}

The PXRD pattern of cobalt hydroxide and cobalt hydroxynitrate samples obtained using sodium hydroxide and urea as precipitating agents are shown in Figs. 1 and 2, respectively. The reflections in the powder X-ray diffraction pattern of cobalt hydroxide (see Fig. 1) match well with $\beta$-phase of cobalt hydroxide (ICSD-26763). Figs. 3(a) and (b) show the thermogram of cobalt hydroxide and cobalt hydroxynitrate, respectively. Cobalt hydroxide loses $14.8 \%$ (expected $13.6 \%$ ) in two steps. The $1.2 \%$ weight loss in the range $35-100^{\circ} \mathrm{C}$ can arise due to physisorbed water (see Fig. 3(a)) and the second step to decomposition of cobalt hydroxide. When cobalt hydroxide sample was isothermally heated at $100^{\circ} \mathrm{C}$, the reflections in the powder X-ray diffraction pattern shows decrease in the relative intensities of all the reflections. At $125^{\circ} \mathrm{C}$, the transformation of cobalt hydroxide to $\mathrm{CoOOH}$ begins to takes place along with trace amount of $\mathrm{Co}_{3} \mathrm{O}_{4}$ (see Fig. 4(a)) as a minor component. The decomposition products of cobalt hydroxide are shown below

$\mathrm{Co}(\mathrm{OH})_{2}+0.25 \mathrm{O}_{2} \rightarrow \mathrm{CoOOH}+0.5 \mathrm{H}_{2} \mathrm{O}$

$3 \mathrm{CoOOH} \rightarrow \mathrm{Co}_{3} \mathrm{O}_{4}+1.5 \mathrm{H}_{2} \mathrm{O}+0.25 \mathrm{O}_{2}$

Electron microscopic studies of cobalt hydroxide, cobalt oxyhydroxide and cobalt oxide shows topotactic relationship between them in spite of being chemically distinct from each other $[12,18]$. The $\mathrm{CoOOH}$ crystallizes in $R-3 m$ or $P 6 / m m c$ space group with an interplanar distance of 4.37 to $4.4 \AA$, while cobalt hydroxide crystallizes in $P-3 m 1$ space group with interlayer

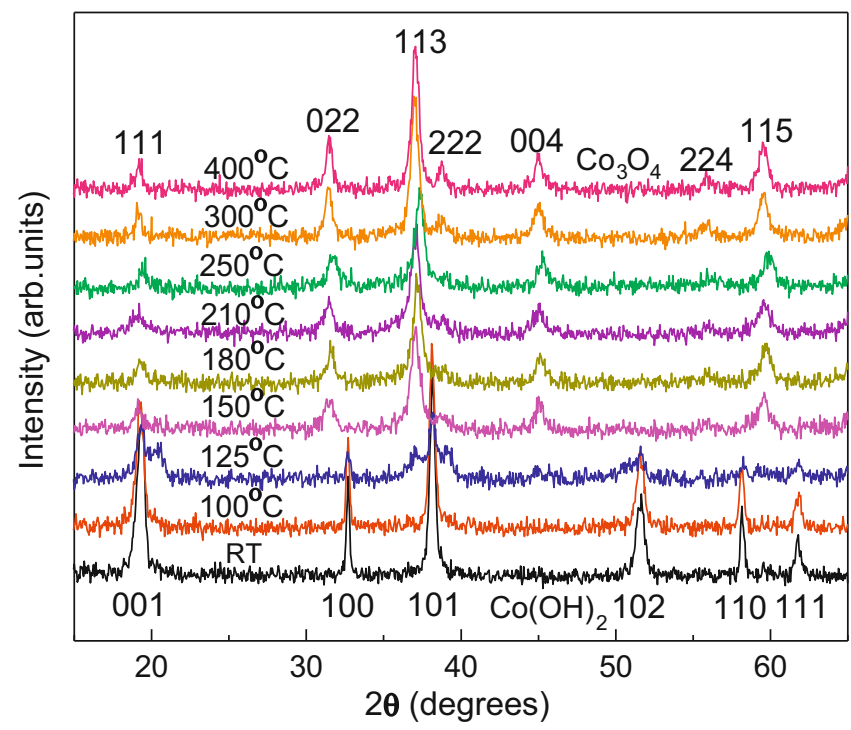

Fig. 1. Cobalt hydroxide heated to different intervals of temperature.

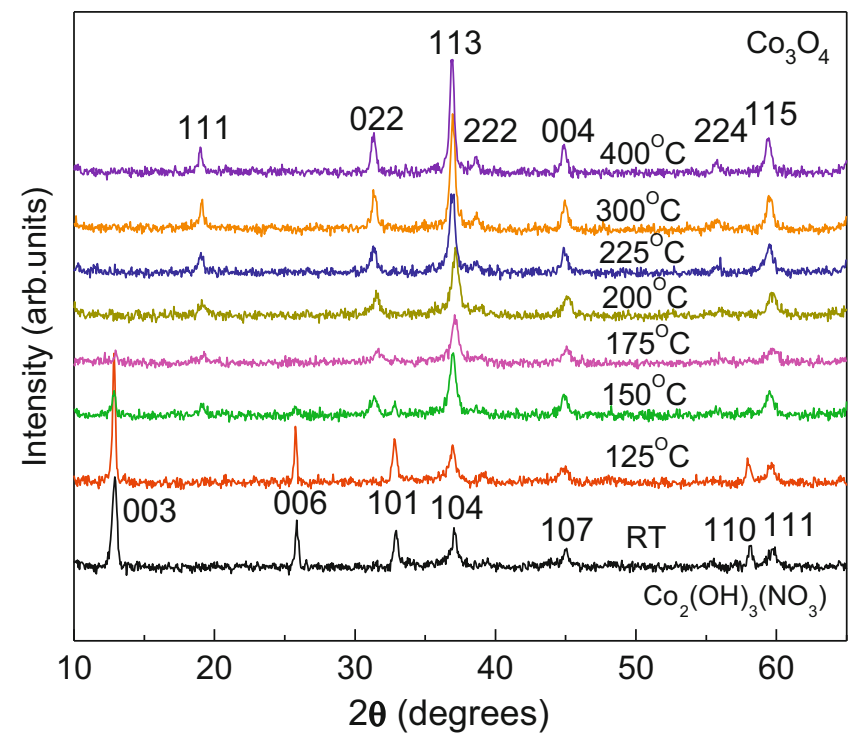

Fig. 2. Cobalt hydroxynitrate heated to different intervals of temperature.

spacing of $4.6 \AA$ [21]. In brucite based layered hydroxides and hydroxysalts, the exact crystal structure is dictated by the stacking sequence of the hydroxyl ions. The polytypism arises due to the translation or rotation followed by translation of layers with respect to each other on a selective stacking direction. Investigation of polytypism in materials science is of contemporary interest to chemists, as it can provide fundamental understanding on the phase transformations of solids in the geological time scale on the earth [22]. Therefore we were interested to investigate the decomposition of cobalt hydroxide and examine the changes that can take place within the stacking sequence of layers. We have described the crystal structure of metal hydroxide in relation to the packing of hydroxyl ions. The upper case symbols A, B and C represents hydroxyl ion positions and lower case symbols $\mathrm{a}, \mathrm{b}$ and $\mathrm{c}$ to cation positions in the metal hydroxide layer. $\mathrm{Co}(\mathrm{OH})_{2}$ can be represented by the symbol $\mathrm{AbC}$ or more simply as $\mathrm{AC}$. Then the brucite structure can be represented by the stacking AC AC AC-layers. ' 1 ' denotes the single layered periodicity and ' $\mathrm{H} / \mathrm{R}$ ' represents for the hexagonal/rhombohedral 


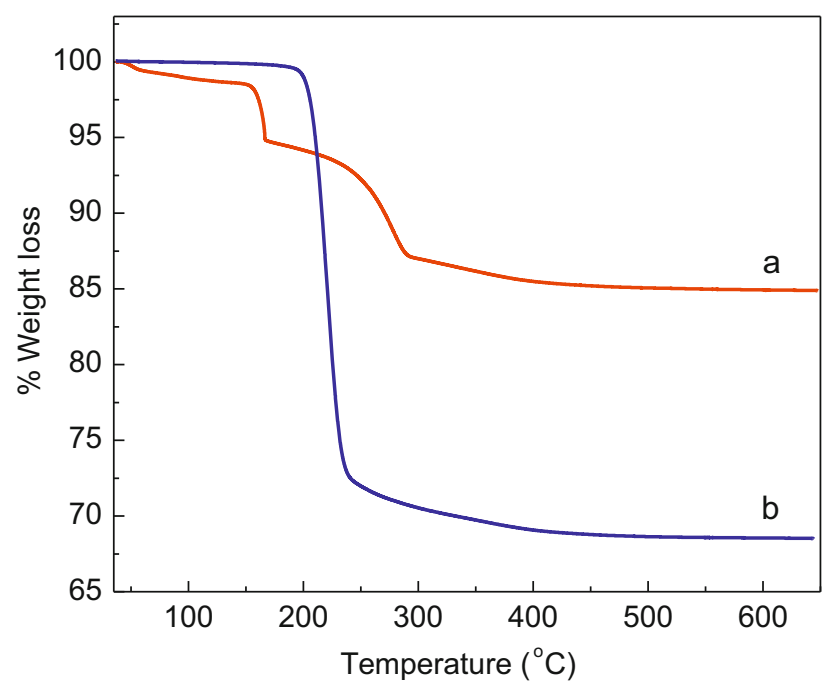

Fig. 3. Thermograms of (a) cobalt hydroxide and (b) cobalt hydroxynitrate respectively.

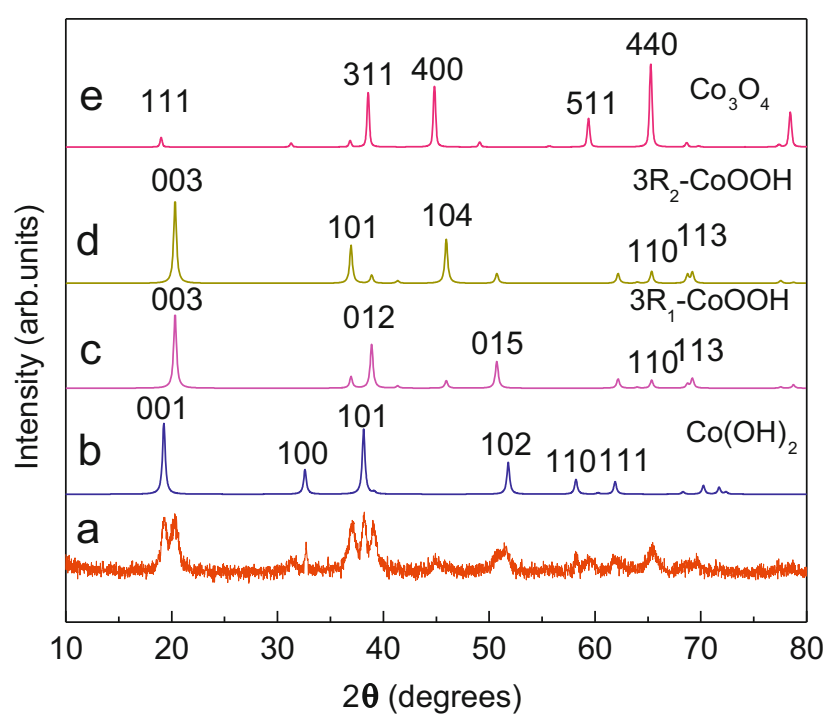

Fig. 4. PXRD pattern of (a) cobalt hydroxide sample heated to $125^{\circ} \mathrm{C}$, DIFFaXsimulated powder XRD patterns of (b) $1 \mathrm{H}$ polytype of cobalt hydroxide, (c) $3 \mathrm{R}_{1}$ polytype of cobalt oxyhydroxide, and (d) $3 R_{2}$ polytype of cobalt oxyhydroxide e) $\mathrm{Co}_{3} \mathrm{O}_{4}$ phase.

stacking sequence. Three different stacking sequences with a two layer periodicities are AC CA AC CA-2 $\mathrm{H}_{1}$; $A C A B A C A B-\mathrm{H}_{2}$ and $A C$ $B A$ AC $B A$ AC $-\mathrm{H}_{3}$ are observed. Structures with 3 layer periodicity having the rhombohedral symmetry exhibit-two sequences i.e. $A C$ $C B$ BA AC- $3 R_{1}$ and $A C B A C B A C-3 R_{2}$. DIFFaX code was used to simulate the PXRD patterns of different polytypes. The relative intensities and peak positions of $(h 0 l) /(0 k l)$ reflections were used as indicators to determine the crystal structure with a selective polytype. The DIFFaX simulated PXRD patterns of $1 \mathrm{H}, 2 \mathrm{H}_{1}, 2 \mathrm{H}_{2}$, $2 \mathrm{H}_{3}, 3 \mathrm{R}_{1}$ and $3 \mathrm{R}_{2}$ polytypes of cobalt hydroxide, cobalt oxyhydroxide and cobalt hydroxynitrate have been reported elsewhere $[11,20]$. Cobalt hydroxide being isostructural with nickel hydroxide crystallizes in $1 \mathrm{H}$ polytype [23]. In cobalt oxyhydroxide phase, the first peak appears at $4.38 \AA$ indicating that the interlayer spacing decreased by $0.22 \AA$ compared to $\beta$-cobalt hydroxide. Fig. 4(b) and (c) shows the simulated PXRD patterns of $3 R_{1}$ and $3 R_{2}$ polytypes of $\mathrm{CoOOH}$ phase. In $3 R_{1}$ polytype $(012)$,
(015) and (018) reflections are relatively strong while (101), (104) and (107) reflections are prominent in $3 R_{2}$ polytype of $\mathrm{CoOOH}$. The cobalt hydroxide heated to $125^{\circ} \mathrm{C}$ shows three peaks in the $35-45^{\circ} 2 \theta$ region. This indicates that there could be intermediate phases formed at $125^{\circ} \mathrm{C}$. The peak positions in the simulated PXRD patterns of $3 R_{1}$ and $3 R_{2}$ polytypes of $\mathrm{CoOOH}$ (see Fig. 4(a), (b) and (c)) matches well with the extra reflections observed at $125^{\circ} \mathrm{C}$. This clearly shows the coexistence of $3 \mathrm{R}_{1}$ and $3 \mathrm{R}_{2}$ polytypes of $\mathrm{CoOOH}$ within cobalt hydroxide phase. We can precisely determine the nature of the polytype formed by simulating the X-ray powder diffraction patterns. The results are interesting in context to cobalt oxyhydroxide samples prepared by chemical methods. Cobalt oxyhydroxide prepared by chemical precipitation tends to form $3 \mathrm{R}_{1}$ polytype [20]. Our results indicate that the $\mathrm{CoOOH}$ in $3 \mathrm{R}_{2}$ polytype forms at $125^{\circ} \mathrm{C}$ as an intermediate metastable phase. During the initial stages of cobalt hydroxide decomposition in presence of air, germination takes place on the edges of the platelets and propagates to the interior regions slowly. The propagation requires sufficient thermal energy in the form of heat and air as an oxidizing agent. The thermal energy initiates half of the protons grafted to hydroxyl groups between the cobalt hydroxide layers to combine with the hydrogen atoms on the neighbouring hydroxyl groups to form water molecules. The water molecules will be eliminated from cobalt hydroxide and during this process cobalt oxyhydroxide phase was formed. During the dehydration process of cobalt hydroxide, the layers are translated with respect to each other thereby generating different polytypes in case of cobalt oxyhydroxide. On increasing the temperature from 125 to $150^{\circ} \mathrm{C}$, the dehydrated interface moves to the interior of each crystallite. The PXRD pattern of cobalt hydroxide heated at $180^{\circ} \mathrm{C}$ shows that pure cobalt oxide phase. On further increasing the temperature from 180 to $400{ }^{\circ} \mathrm{C}$ the peak widths of all the reflections decreases indicating an increase in the crystallinity of the $\mathrm{Co}_{3} \mathrm{O}_{4}$. Fig. 5 shows the schematic representation of cobalt hydroxide to cobalt oxide transformation mechanism in relation to translation and rotation followed by translation of layers with respect to each other.

In Fig. 3 is shown the thermogram of cobalt hydroxynitrate sample. It shows a single step weight loss of $31.4 \%$ (expected $30.4 \%$ ). The decomposition reaction of cobalt hydroxynitrate would be of interest, since it has a combination of an oxidizing agent as intercalant (nitrate) within the interlayer and an oxidizable transition metal [24]. When the sample was heated to higher temperature, the nitrate ion grafted to the metal ion decomposes; during this process transition metal ion will change its oxidation state. Cobalt hydroxynitrate is an ideal candidate with a nitrate anion as an oxidant being anchored to the sheets of metal hydroxide. The chemical formula of cobalt hydroxynitrate is $\mathrm{Co}(\mathrm{OH})_{1.5}\left(\mathrm{NO}_{3}\right)_{0.5}$ compared to $\mathrm{Co}(\mathrm{OH})_{2}$. There is less number of protons in the interlayer spacing of cobalt hydroxynitrate in relation to cobalt hydroxide. Fig. 2 shows the cobalt hydroxynitrate sample heated to different intervals of temperature. We observe two phase mixture of cobalt oxide and cobalt hydroxynitrate at 125 and $150{ }^{\circ} \mathrm{C}$, respectively. The cobalt hydroxynitrate $(6.9 \AA)$ to $\mathrm{CoOOH}(4.38 \AA)$ transformation is not favored due to (a) the presence of less number of hydrogen atoms within the interlayer, (b) drastic mismatch between the interlayer spacings, and (c) nitrate being an oxidizing agent promotes to the formation of cobalt oxide directly compared to $\mathrm{CoOOH}$ phase. At $175^{\circ} \mathrm{C}$, cobalt hydroxynitrate peaks completely disappear and cobalt oxide phase are observed. In $150-350{ }^{\circ} \mathrm{C}$ range, the relative intensities of cobalt hydroxynitrate phase decreases and intensities of cobalt oxide peaks increases. Fig. 5 shows the schematic representation of cobalt hydroxynitrate transformation to cobalt oxide. 


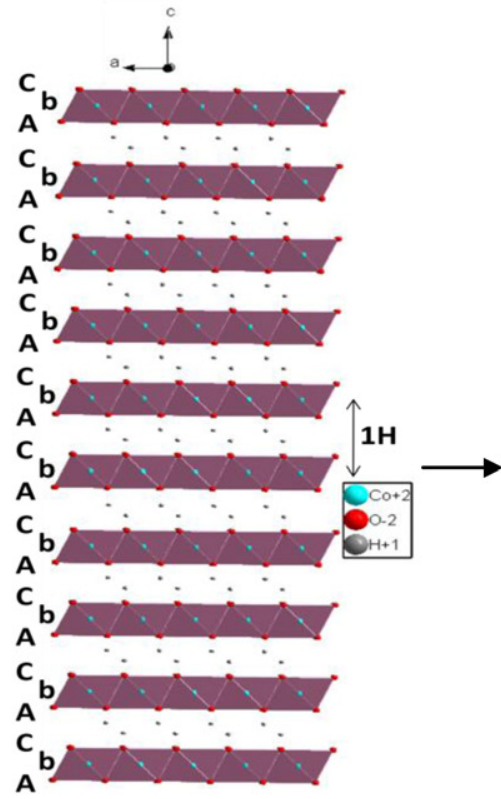

$\mathrm{Co}(\mathrm{OH})_{2}$ at room temperature

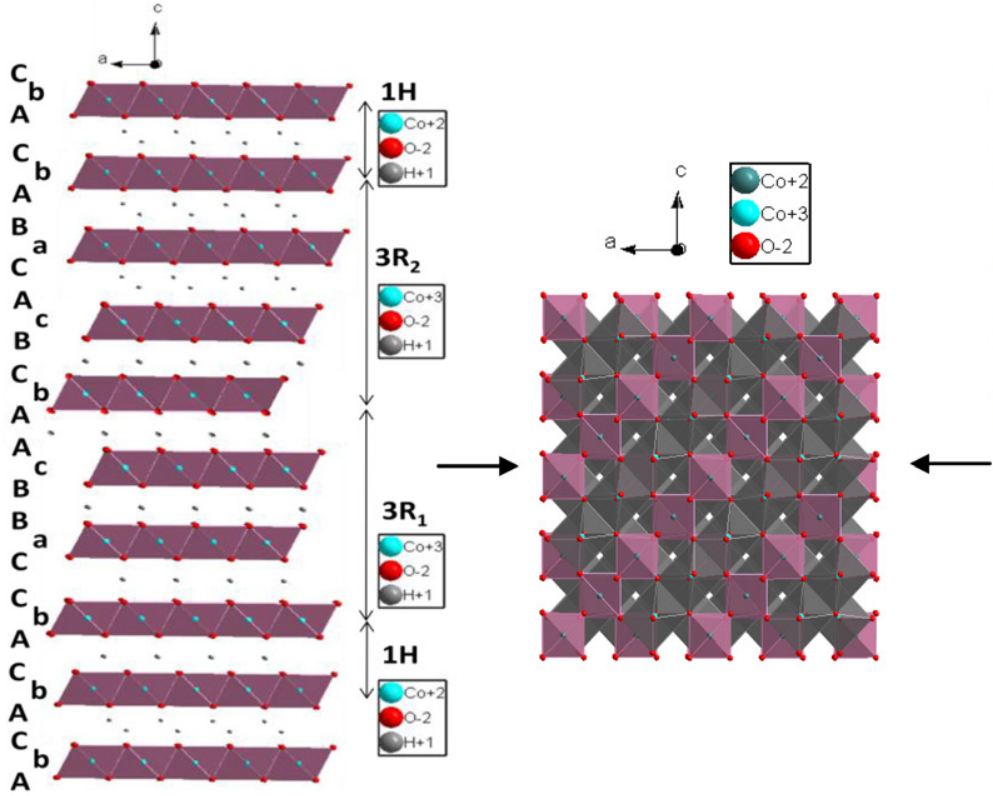

$\mathrm{Co}_{3} \mathrm{O}_{4}$ at $180^{\circ} \mathrm{C}$

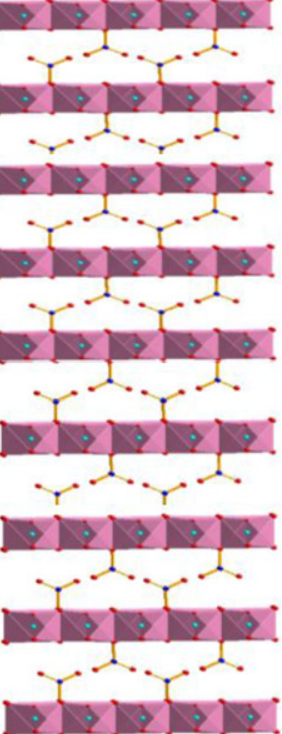

$\mathrm{CO}_{2}(\mathrm{OH})_{3}\left(\mathrm{NO}_{3}\right)$ at room temperature

Fig. 5. Schematic representation on the structural transformation of cobalt hydroxide at room temperature and $125^{\circ} \mathrm{C}$, cobalt hydroxynitrate and cobalt oxide.

\section{Conclusions}

This work enables us to demonstrate that the cobalt oxide spinel $\left(\mathrm{Co}_{3} \mathrm{O}_{4}\right)$ formed during the thermal decomposition process can be dictated by the nature of the precursor used. The mechanism of multiphase or two phase decomposition can be controlled by the choice of the precursor with or without orientational relationship to the spinel phase and polytype.

\section{Acknowledgements}

T.N.R. thanks the Council of Scientific and Industrial Research, GOI for the award of a Research Associate Fellowship. Author gratefully thanks Prof. P. Vishnu Kamath for providing laboratory facilities to carry out the work and his encouragement to publish the results. I also thank B. E. Prasad for recording XRD patterns. The author also thanks reviewers for their valuable suggestions.

\section{References}

[1] M.E. Brown, D. Dollimore, A.K. Galwey, in: Bamford, C.F.H. Tipper (eds.), Reactions in Solid State-Comprehensive Chemical Kinetics, Vol. 22, Elsevier, Amsterdam, 1980, Ch. 2.

[2] M. Fantini, A. Gorenstein, Sol. Energy Mater. 16 (1987) 487.

[3] M.-A. Wu, H.-H. Hiseh, Electrochim. Acta 53 (2008) 3427.
[4] G. Guadalupe, C. Arizaga, K.G. Satyanarayana, F. Wypych, Solid State Ionics 178 (2007) 1143.

[5] S.U. Falk, A. Salkind, Alkaline Storage Batteries, Wiley, New York, 1969.

[6] H.R. Oswald, R. Asper, in: Preparation and crystal growth of materials with layered structures, Vol. 1, D. Reidel Publishing Company, Dordrecht, 1977, p. 71.

[7] M. Rajamathi, G.S. Thomas, P.V. Kamath, Proc. Indian Acad. Sci 113 (2001) 671.

[8] E. Khandare, in: Development of 2-D nanostructured layered hydroxy salts (LHSs) and hydroxy double salts (HDSs) for new applications: anionic exchange kinetics and polymer modification, Marquette University, 2006.

[9] A.F. Wells, Structural Inorganic Chemistry, Oxford University Press, Oxford 1979.

[10] T.N. Ramesh, M. Rajamathi, P.V. Kamath, Solid State Sci. 5 (2003) 751

[11] T.N. Ramesh, M. Rajamathi, P.V. Kamath, J. Solid State Chem. 179 (2006) 2386.

[12] M. Figlarz, J. Guenot, F. Fievet-Vincent, J. Mater. Sci. 11 (1976) 2267.

[13] V. Pralong, A. Delahaye-Vidal, B. Beaudoin, B. Ge'rand, J-M. Tarascon, J. Mater. Chem. 9 (1999) 955

[14] X. Lu, R. Yi, N. Zhang, R. Shi, X. Li, G. Qiu, Chem. Asian J. 3 (2008) 732.

[15] Y. Hou, H. Kondoh, M. Shimojo, T. Kogure, T. Ohta, J. Phys. Chem. B. 109 (2005) 19094.

[16] L. Hernan, J. Morales, A. Ortega, J.L. Tirado, J. Therm. Anal. 29 (1984) 491.

[17] S. Kittaka, N. Uchida, I. Miyashita, T. Wakayama, Colloids Surf. 37 (1989) 39.

[18] M. Figlarz, D. Guenot, J.-N. Tournemolle, J. Mater. Sci 9 (1974) 772.

[19] R.L. Frost, J. Yang, W.N. Martens, H. Liu, J. Phys. Chem. C. 114 (2010) 111.

[20] T.N. Ramesh, Inds. Eng. Chem. Res. 49 (2010) 1530.

[21] M. Delians, H. Goethals, Miner. Mag. 39 (1973) 152

[22] A.R. Verma, P. Krishna, Polymorphism and Polytypism in Crystals, John Wiley New York, 1966.

[23] T. N Ramesh, P.V. Kamath, C. Shivakumara, Acta Cryst. B 62 (2006) 532.

[24] R. Xu, H.C. Zeng, Chem. Mater. 15 (2003) 2040. 